\title{
2. 'Thus have been preserved numerous interesting facts that would otherwise have been lost': Colonisation, protection and William Thomas's contribution to The Aborigines of Victoria
}

\author{
Rachel Standfield
}

Robert Brough Smyth, Chairman of the Central Board for the Protection of Aborigines, published his The Aborigines of Victoria: with notes relating to the habits of the Natives of other parts of Australia and Tasmania, compiled from various sources for the Government of Victoria in 1878. ${ }^{1}$ Smyth's work is an example of an early Australian anthropological text. It is a large work, over two volumes and 938 pages, and collected together information gathered from multiple observers of Aboriginal life and society in Victoria and further afield. Smyth, as a noted colonial scientist as well as chairman of the Protection Board, was well placed to collate the work, and contribute to the burgeoning interest in collecting Aboriginal artefacts and documenting aspects of Aboriginal culture. In 1861, the President of the Royal Society of Victoria 'called for urgent research into Aboriginal "dialects and traditions" as whole tribes "are, under some mysterious dispensation, rapidly disappearing"' ${ }^{2}$ While the publication took a very long time to come to fruition, when it was published it was disseminated publicly at the expense of the Victorian colonial government, who distributed it to libraries and mechanics institutes. ${ }^{3}$

As well as taking significant time, the text was also the product of a significant number of contributions by a number of European observers of Aboriginal culture, including John Green, William Ridley and AW Howitt. The first source mentioned in Smyth's preface was William Thomas, Protector of Aborigines in the Aboriginal Protectorate in Port Phillip from 1839, Guardian of Aborigines when the original Protectorate was abolished, and involved in the Central Board

\footnotetext{
1 Robert Brough Smyth, The Aborigines of Victoria: with notes relating to the habits of the Natives of other parts of Australia and Tasmania compiled from various sources for the Government of Victoria, Melbourne, Government Printer, 1878.

2 Richard Broome, Aboriginal Victorians: A History Since 1800, Allen \& Unwin, Sydney, 2005: 100.

3 Broome, Aboriginal Victorians: 101.
} 
for Protection of Aborigines during the 1860s, but with a role that was curtailed by ill health. Thomas died in 1867, well before the publication of Smyth's work, but Smyth described Thomas's contribution in the following terms:

When I commenced to figure and describe the native weapons, I asked the late Mr William Thomas ... to write down under separate heads all that was known to him respecting the Aborigines; and thus have been preserved numerous interesting facts that would otherwise have been lost. ${ }^{4}$

'Collated texts' of the last quarter of the nineteenth century, like Smyth's work, Roger Lawrence concludes, are of limited use for understanding the connection between Aboriginal people and their environment from an anthropological perspective, because of the speed with which the material was collected and selective decisions to include material considered interesting or useful. ${ }^{5}$ These collated texts do, however, offer an opportunity to trace the ways that knowledge was developed, reworked and remade in response to changing colonial circumstances and different contexts of colonial governance. In this chapter, I consider the contribution made by Thomas to Smyth's text, analysing Thomas's material and a notebook of collated material and looking at the way they were used in Smyth's work.

Exploring Smyth's collated text from the perspective of a selection of contributed material allows a view to emerge of the shifting currents of European thought in relation to Aboriginal people and culture, particularly from the perspective of changing systems for the governance of Aboriginal communities in Victoria. Through this chapter, I examine the way that Thomas's observations, with their particular emphasis on his early years of work with the original Port Phillip Protectorate, are utilised in a text associated with the second period of protection in Victoria, but one that was also written within an anthropological discourse.

Having worked with Thomas's papers housed in the Mitchell Library, my interest is in following the way that his views of Aboriginal people and their culture were reworked in this anthropological work. This chapter explores the way that Thomas's material, both from his own observations and that collated by Thomas for Smyth, was used within the published work, considering the way that observations drawn from one period of 'protection' of Victorian Aboriginal communities were utilised in a document borne from another. Thomas's ethnographic observations, largely based on his experiences living

4 Smyth, The Aborigines of Victoria, Preface: v-vi.

5 Edward Curr, The Australian Race: Its Origin, Languages, Customs, Place of Landing in Australia, and the Routes by Which It Spread Itself Over That Continent, Government Printer, Melbourne, 1886-1887; Roger Lawrence, 'Habitat and economy: a historical perspective', in DJ Mulvaney and J Golson (eds), Aboriginal Man and Environment in Australia, Australian National University Press, Canberra, 1971: 252. 
with Indigenous people in the late 1830s and 1840s, while working as Assistant Protector in the Port Phillip Protectorate, were reworked to fit the anthropological text published in the context of the Aborigines Protection Act 1869 (Vic). This chapter traces shifts from humanitarian discourses of the early period of protection in Victoria, which had often been critical of colonisation, to an academic discourse which while using these earlier sources, effaced their colonial dimension, in the search for a 'pure' anthropological type. Smyth, while 'preserving' Protectorate material he feared would be lost, also excised and reworked material about Aboriginal people and their social arrangements and culture. Thomas's writing often captured Aboriginal agency and Aboriginal resistance, but Smyth stripped this material of almost all aspects of the particularities of Aboriginal experience and engagement in the processes which governed their lives. In this sense, the chapter argues that Smyth's work is simultaneously an academic text and one related to processes of colonial governance, combining representation of Indigenous peoples from an anthropological perspective with discussions of governance and colonial history suited to the context of colonial governance in which the text had been developed and into which it was published. As Gillian Cowlishaw describes, anthropology as a discipline reflects both a critique of inequality and a 'deep complicity' with colonial discourses and power relations. Cowlishaw argues that two factors mitigate against anthropology's moral program of encouraging respect for Aboriginal culture - a focus on 'traditional Aboriginal society' and the manner in which anthropological texts ignore, or support, 'aggressive assimilationism' by governments. ${ }^{6}$ This connection was perhaps even more pronounced with Smyth's text, being compiled 'from government records' by a scholar with deep connection to Victorian governance of Aboriginal people.

Ann Laura Stoler builds a powerful argument that the colonial archive is not merely a site of knowledge collection but also one of knowledge production. ${ }^{7}$ Stoler's work looks at archives as 'cross-sections of contested knowledge', encouraging scholars to pay close attention to 'what subjects are cross-referenced what parts are re-written, what quotations are cited' as they 'not only tell about how decisions are rendered, but how colonial histories are written and remade'.$^{8}$ The archive examined here is a small part of a collection of papers, and yet, in examining this part of the Robert Brough Smyth collection, it is possible to see the impact that Thomas's contributions can make in Smyth's text, the way that they are utilised and employed to create new knowledge about Aboriginal people, to serve new needs in intellectual communities as well as, I argue here, in terms of governance of Aboriginal people. Stoler's work

6 Gillian Cowlishaw, 'Studying Aborigines: changing canons in anthropology and history', Journal of Australian Studies 16(35), 1992: 20.

7 Ann Laura Stoler, 'Colonial archives and the arts of governance', Archival Science 2, 2002: 87-109.

8 Stoler, 'Colonial archives and the arts of governance': 87, 107. 
focuses on commissions, collections of statistics, and classification of state secrets, but by analysing a small portion of the archive of material that helped to form Smyth's texts it is possible to trace similar practices of the remaking and reworking of colonial knowledge, knowledge that was derived from an earlier system of colonial governance and applied to an emerging academic discipline, by an author himself connected to governance of Indigenous peoples.

Nicholas B Dirks, in examining the construction of works of 'pre-British Indian history' during the colonial period of Indian history, traces the way that European collectors, compilers and authors of these works made use of earlier material collected in the encounter between agents of empire and native peoples. Dirks read history back in to discourses which deny history to and essentialise colonised peoples, by interrogating the processes whereby the 'pasts of the colonized ... were erased as soon as conquest made possible the production of new forms of knowledge that endowed colonialism with natural legitimacy'. ${ }^{9}$ Dirks looks further back than 'texts of high imperialism' to examine the 'competing histories' created 'before colonized histories were ensnared and silenced' ${ }^{10}$ He looks for

the ambivalences and contests within early colonial historicities, imagined when colonial historiographies were still dependent upon native informants and colonial histories were still unsecured by the political triumphs that made possible the illusion of permanence ... Erasures were written over histories that were being actively recovered and rewritten at the same time they were being transformed into histories of loss and subjection. Mythical discourses were constructed out of historical encounters. ${ }^{11}$

Dirks traces the impact of these encounters, and the relationship between the European observer and the 'native informant' on later texts, and it is my aim here to apply the same approach to Smyth's text through an examination of the influence of Thomas's writing on his work. For Thomas's position and the knowledge derived from it was heavily 'dependent' upon 'native informants' ${ }^{12}$ Thomas, spent much of his early career living amongst the Woiwurrung and Boonwurrung communities and engaging with other Kulin peoples as they visited Melbourne. These experiences provided the basis of the information he provided for The Aborigines of Victoria and he was thus clearly indebted to his relationships with Aboriginal people for the ethnographic information he could

\footnotetext{
9 Nicholas Dirks, 'Colonial histories and native informants: biography of an archive', in Carol Breckenridge and Peter van der Veer (eds), Orientalism and the Postcolonial Predicament: Perspectives on South Asia, University of Pennsylvania Press, Philadelphia, 1993: 280.

10 Dirks, 'Colonial histories and native informants': 280.

11 Dirks, 'Colonial histories and native informants': 280.

12 Dirks, 'Colonial histories and native informants': 280.
} 
contribute. These relationships, and the debt he owed to them, will be explored further in this chapter through an examination of material Thomas provided to Smyth and work within his own archive of papers, which appears developed for publication.

The publication of Smyth's two volumes occurred within the context of the establishment of the reserve system in Victoria and the passing of the 1869 Act, the first such Act in the Australian colonies, and the model for other colonial legislation to come. As Leigh Boucher and Lynette Russell have shown, this context of colonial governance allowed men of standing in Victoria to rest in the knowledge that 'the legislation effectively disbursed the moral obligation of settlers', after a period through the 1850s and 1860s when the 'nascent intellectual elite returned again and again to the moral problems of colonial expropriation'. ${ }^{13}$ The sense of development towards 'progressive' legislation aimed at protecting Victorian Aboriginal people was palpable in Smyth's text. In the introduction to the work Smyth applauded the work of government on behalf of Aboriginal people (which he himself had, of course, been a part of), with the government having 'done much to benefit them'. Smyth, after documenting the rapid depopulation of Aboriginal communities, turned quickly to recognise the exertions of a lineage of Europeans who had worked to 'ameliorate the condition of the native that survived the first contact with the vices and contamination of the whites' ${ }^{14}$ Not only Secretaries of State for the Colonies or members of the Parliament of Victoria were applauded, but also missionaries - 'able, earnest and thoughtful men' - and 'gentlemen in Victoria - clergymen' who had 'voluntarily sacrificed all hopes of preferment, and have devoted their lives to the task of ameliorating the condition of our native population'. The previous system of appointing Guardians during the 1850s had not had results 'such as to satisfy the colonists' and Smyth concluded that the condition of Aboriginal people had been 'deplorable'; he could turn, however, to the 1858 Victorian Select Committee on Aborigines, the establishment of the Board, and the 1869 Act to provide for Aboriginal 'protection and management' as examples of progressive colonial governance. The parliament had been 'liberal in its grants of money' with Smyth suggesting that $£ 100,000$ had been spent on the system implemented since the 1858 Select Committee. ${ }^{15}$ Thus the move to a 'moral' and 'progressive' system of governance allowed the author to be freed from any guilt of the failure of previous systems of governing the Indigenous population, and lent the text a congratulatory tone.

13 Leigh Boucher and Lynette Russell, "'Soliciting sixpences from township to township": Moral dilemmas in mid-nineteenth-century Melbourne', Postcolonial Studies 15(2), 2012: 161, 150.

14 Smyth, The Aborigines of Victoria: $\mathrm{xx}$.

15 Smyth, The Aborigines of Victoria: xx. 
Boucher and Russell also demonstrate that this new context of colonial governance had two impacts on Aboriginal people in Victoria, by offering both respite to communities 'from the onslaught of land-hungry and often violent settlers', while simultaneously depriving Aboriginal people of their ability to move throughout the colony and leading to increasing levels of government interference into Aboriginal lives. In removing Aboriginal people from urban spaces to reserves, Aboriginal bodies and voices were no longer constant reminders of dispossession, largely finishing a project of removing Indigenous people from the Melbourne environment which had constituted a core part of William Thomas's role from as far back as $1840 .{ }^{16}$ In Smyth's text, increasing levels of government control were portrayed as natural and inevitable. Smyth's introduction included a short summation of colonial history, and it is one in which, while acknowledging settler violence, suggests that conflict between communities after white settlement was the principal form of conflict.

Firstly, Smyth described Europeans as 'invaders', providing a clear sense of contest over land in his description, but this contest, he felt, had changed Aboriginal communities. As colonisers 'established' themselves, 'and the natives were driven first from one spot and then from another' to make way for cattle and sheep, Indigenous people were mixed together - 'compelled to mingle' - in a way that had not been known before colonisation. The consequences of this, Smyth considered, were dire for Indigenous people and their culture:

The ancient land marks were obliterated, the ancient boundaries had ceased to have any meaning, and the people, confused and halfstupefied by the new and extraordinary character of the circumstances so suddenly forced upon them, almost forgot the duties their tribal laws imposed upon them when they were brought face to face with strange blacks. ${ }^{17}$

Smyth thus suggested that as Aboriginal communities lost access to land and were thrown into new connections with other Aboriginal communities they simultaneously lost knowledge of country, that country lost its significance to Aboriginal cultures, and the people were merely confused and bewildered. Indigenous people have lost all agency here, they, according to Smyth, ceased upon colonisation to act deliberately or to defend themselves or their country. They were 'unable', he wrote, 'to combine and offer determined resistance to the invaders' but instead became 'the more savage and cruel', and this 'compelled' settlers to make reprisals. ${ }^{18}$

16 Boucher and Russell, 'Soliciting sixpences from township to township': 162; Broome, Aboriginal Victorians: 120.

17 Smyth, The Aborigines of Victoria: xviii-xix.

18 Smyth, The Aborigines of Victoria: xix. 
Moreover, the actions of 'the rifle and the pistol' were less dangerous to Aboriginal people than disease and 'vice', such that it was the 'kindness of the civilised immigrant that swept off the native population', through the introduction of alcohol and 'attentions' to Aboriginal women. ${ }^{19}$ Disease and the relationship between Aboriginal people and the colonial medical establishment became important to the text, alongside a strong theme of 'superstition'. Such emphases accord to the conclusions of Patrick Brantlinger, who stresses the centrality of accounts of disease and superstition within dying race discourses (which neccesarily downplayed the role of violence or European agency in the decline of Indigenous populations). ${ }^{20}$ This is a point I shall return to in more detail later in this chapter.

While Smyth concluded that these European responses were 'not much to the credit of Europeans', he consigned them to 'the olden time'.$^{21}$ Thomas's material, being largely based on his experiences in the first period of Protection in what was then the Port Phillip District of the Colony of New South Wales, belonged to this earlier period. In Smyth's text, Thomas's observations represented a 'traditional' and 'authentic' Aboriginal culture on the cusp of the degradation caused by European contact and the loss of culture. Thomas appears to have provided a significant amount of material to Smyth. ${ }^{22}$ Some letters in the Thomas papers are addressed to Smyth particularly and other material in his papers, included directly after the letters to Smyth, appear to have been annotated by Thomas and sent on. As well as contributing work from his own papers, Thomas gathered information. A notebook of this collected material is included within Smyth's papers in the State Library of Victoria. Running to 129 pages, it collates information gathered from different earlier sources, including material from Thomas Mitchell's exploration journals, published material on Aboriginal life from Victorian newspapers, and undated material from the Port Phillip Protectorate that has since been identified as the work of Assistant Protector James Dredge. ${ }^{23}$ This, Fels suggests, is Thomas 'doing anthropology'. ${ }^{24}$

If we consider the presentation of Thomas's ethnographic information in Smyth's text, by taking as an example the depiction of Aboriginal weaponry, however, we can see the way that the processes of collating, cataloguing and editing Thomas's contribution worked to strip Aboriginal cultural information from this anthropological text. Smyth was particularly interested in weaponry,

\footnotetext{
19 Smyth, The Aborigines of Victoria: xix.

20 Patrick Brantlinger, Dark Vanishings: Discourse on the Extinction of Primitive Races, 1800-1930, Cornell University Press, Ithaca and London, 2003.

21 Smyth, The Aborigines of Victoria: xix.

22 In the papers which survive from Thomas's long career, there is a significant amount of writing which he had provided to others, including material provided to La Trobe for use in a book.

23 Marie Hansen Fels, 'The La Trobe library collection of the papers of Assistant Protector William Thomas',

The La Trobe Journal 43, Autumn 1989: 14.

24 Fels, 'The La Trobe library collection of the papers of Assistant Protector William Thomas': 14.
} 
and had initially gone to Thomas to ask for his input in his project to 'figure and describe the native weapons'. Subsequently, in providing information to Smyth, he focused on the importance of the use of weaponry and the role of conflict within Victorian Aboriginal culture; the particularly organised and ritualised nature of conflict, the presence of 'commanders' and the role of older men to manage conflict so that inter-clan relationships were generally restored without people coming to serious harm. He concluded of the resolution of conflict: 'There is an affecting feature after all. Combatants may be seen sucking each others wounds and spitting the blood from them.' ${ }^{25}$ These insights were based on his observations of Kulin communities coming together for ritual conflict. He had initially tried to intervene to stop such conflict, and was physically removed and protected on one occasion by members of the communities he lived with, and had come to understand conflict as highly organised and with important cultural functions in ensuring the smooth running of clan relations.

The drawings of Aboriginal weaponry were reproduced in Smyth's text, with the features of the weapons being compared to descriptions by other European observers in other parts of the continent. In the process of including these images, beautifully presented though they were, the accompanying cultural information about the way that Aboriginal people used the weapons was removed from the images, some of it being woven into other parts of the text. The visual presentation of these allowed Smyth to explore the scientific and comparative aspects of Victorian Aboriginal weaponry, but strip out all sense of Aboriginal culture, reworking the information in another part of the text. As Lynette Russell describes, 'the failure to provide the necessary detail or text required to appreciate the object and its context - to hear its story - is a common omission in museum displays' and I would argue that the same is true in this text. ${ }^{26}$ Within the development of the text, the cataloguing and classification of objects of material culture have taken on more importance than understanding their cultural context, their function in social life and community relationships, or indeed the context of encounter out of which European understanding of that significance was generated. Instead, selected information was paraphrased in the section entitled 'fights' within the chapter devoted to 'a native encampment, and the daily life of the natives'. Smyth included descriptions from William Buckley as well as Thomas, 'because there are probably not very many now living who have seen a well-contested fight, after the Aboriginal fashion, in this colony', ${ }^{27}$ but not before he had drawn his own quite lurid picture of Aboriginal inter-clan conflict. He described Aboriginal conflict as 'not a brawl ... but generally a well-devised set-to between the fighting men of each side'

25 Thomas papers in the Mitchell Library, MS214, volumes 21 and 22, frame 136.

26 Lynette Russell, Savage Imaginings: Historical and Contemporary Constructions of Australian Aboriginalities, Australian Scholarly Publishing, Melbourne, 2001: 11.

27 Smyth, The Aborigines of Victoria: 157. 
after which 'they come out ... most often scatheless', and yet the description itself is of disorder and savagery. Smyth focuses on 'the decorations of the warriors', naked except for paint and feathers, 'loud cries', 'shaking' of spears', 'rattling' of clubs, the 'violent motions of the warriors and their savage yells', combined with the 'yells and screams of the women and children' as 'wives rush in to protect their husbands and mothers cling to their sons to shelter and help them'. He suggests that such a scene would 'create alarm' for 'one new to the country'.$^{28}$ Thomas's discussion of wound care was used as evidence that no matter how much the scene might 'induce disgust and abhorrence, they are not altogether devoid of those elements which serve to elevate our species' ${ }^{29}$ Smyth's collating and categorisation of the information provided by Thomas, which Stoler might describe as 'information out of place' that 'underscores what categories matter', suggests that depicting material culture was of primary importance, with Smyth collecting objects of material culture to be catalogued, but excising the supporting context which explained Aboriginal life and could counter depictions of 'savagery'. ${ }^{30}$

While some information was 'out of place', other contextualising material was not used at all, but sifted through for the 'facts' of Aboriginal life. Assistant Protector Dredge's writing, included in Thomas's notebook amongst the Smyth papers, was clear about colonisation and the crisis it had engendered amongst the Aboriginal communities that he was sent to protect. Information in Dredge's papers did mirror that which Smyth eventually used, but, as the following example in relation to Aboriginal food resources might illustrate, the 'facts' were provided without reference to colonial intrusion into Aboriginal life. Dredge described 'Murnong', a staple Aboriginal food source, but quickly turned to a description of how the loss of Murnong had been felt by Aboriginal communities:

In the unlocated parts of the country and such other places as have not been visited by the flocks and herds of the settler these roots are obtained in great abundance but like the other natural supplies of the Aborigines they diminish and soon disappear when sheep and cattle are depastured. Nor are the Natives insensible of the cause of such diminution. $^{31}$

28 Smyth, The Aborigines of Victoria: 156.

29 Smyth, The Aborigines of Victoria: 156.

30 Stoler, 'Colonial archives and the arts of governance': 107.

31 William Thomas, undated notebook within the Robert Brough Smyth papers, State Library of Victoria (SLV) MS 8781, Box 1176/6: 97. 
Dredge included a quote from an Aboriginal person in Melbourne that registered Aboriginal protest at the loss of food resources, which he translated thus 'no Murnong, no yam at Port Phillip, too much by one white man Bullock and sheep, all gone Murnong \& $\mathrm{c}^{\prime} .^{32}$

Smyth's treatment of this information was to excise all discussion of colonial process and Aboriginal perspectives on the loss of their resources. The same descriptions of Murnong are employed, the role of women and children in gathering the resource and the seasons in which it was gathered, and descriptions of the likeness to Europeans vegetables come from Dredge's material:

Murr-nong or Mirr-n'yong, a kind of yam (Microseris Forsteri), was usually very plentiful and easily found in the spring and early summer, and was dug out of the earth by the women and children. It may be seen growing on the banks of the Moonee Ponds, near Melbourne. The root is small, in taste rather sweet, not unpleasant, and perhaps more like a radish that a potato. This plant grows throughout the greater part of extra-tropical Australia - and in Tasmania and New Zealand. ${ }^{33}$

All information about Aboriginal food gathering during colonial contact was removed, along with any sense of Aboriginal protest at the loss of the resource, replaced instead by scientific information about the diversity and extent of plant growth, not only in Victoria but in Tasmania and New Zealand.

Similarly, Dredge's papers included very important information about the way that Aboriginal communities recorded and communicated colonial experiences:

They have a species of historical song which enumerates to a monotonous tune, the individual beating time by striking a couple of sticks together or beating with his hand upon his breast, the most material circumstances wished to be remembered. I have known a blackfellow lie on his back and sing to himself for an hour together, or till he had fallen asleep, about the coming of white fellow, the first appearance of the horse, bullock, wheelbarrow (cart), dog, sheep, flour \&c \&c and a great variety of other matters, indeed it is not unusual to hear them at their various fires when encamped for the night humming these things over till sleep overcomes them. ${ }^{34}$

32 William Thomas, undated notebook within the Robert Brough Smyth papers, SLV MS 8781, Box 1176/6: 97-98.

33 Smyth, The Aborigines of Victoria: 209, 'Food'.

34 William Thomas, undated notebook within the Robert Brough Smyth papers, SLV MS 8781, Box 1176/6: 105. 
Descriptions such as these in the Protectorate material connect clearly to processes of colonisation. They show Aboriginal people remembering and reflecting on the momentous processes of change wrought by colonisation, and processes of oral histories within communities.

There was a natural place for this material in Smyth's text, in the chapter on 'encampment and daily life' which had a section describing a scene of an Aboriginal encampment at night:

the old men and the old women devoted their evenings to conversation - and strange stories were told of phantoms and dim forms that had affrighted them in their journeys and when camping. The priests lost no opportunity of exercising and extending their influence, and many a night a camp was kept awake by the vagaries of some sorcerer. He would pretend to fly; he would pretend to bring wild blackfellows to the camp, he would make hideous noises and terrify the natives ... ${ }^{35}$

And yet there was no description here of the remembrance of colonisation, of the committing to oral history the coming of white settlement. Instead, the focus of Smyth's text was on sorcery and superstition, rather than on Aboriginal people as active agents in colonial histories; it depicts Aboriginality as radically 'other' from the non-Indigenous community, rather than as people engaged in colonial situations remembered through distinct forms of historical remembrance.

Some of the most important observations on Aboriginal culture included in the Smyth text came directly from Thomas, particularly in connection to Aboriginal relationships to country, and descriptions of political leadership. Thomas's map of Aboriginal spatial arrangements was reproduced in the section on 'encampment and daily life'. ${ }^{36}$ The map was based on Thomas's observations of the regular gatherings of the five nations of the Kulin alliance in Melbourne in the early years of the first Protectorate, while Smyth described how 800 people had gathered on the occasion when Thomas had produced his map. ${ }^{37}$ While it was reproduced in the book in a simplistic manner, the value of this map, as Marie Fels describes is:

This drawing is a representation on one plane of a birdseye view of an encampment when different tribes congregated together. Its huge significance lies in the fact that the map on the ground stands for or represents existing relationships of country, and, within relationships of country, social distance relative to family and powerful leaders. ${ }^{38}$

35 Smyth, The Aborigines of Victoria: 178-179.

36 Smyth, The Aborigines of Victoria: 124.

37 Smyth, The Aborigines of Victoria: 124.

38 Fels, 'The La Trobe library collection of the papers of Assistant Protector William Thomas': 13. 
Thomas's map led Smyth to conclude that ' $[t]$ he Aborigines do not herd together promiscuously. There is order and method. ${ }^{39}$ Systems of Aboriginal leadership were also described in Smyth's text: 'the encampments of the natives, and indeed all their movements, are ordered by the old men.' ${ }^{40}$ The theme of order in communities came through again, linked to Aboriginal leadership: 'They do not wander about aimlessly: there is order and method in what they do.' ${ }^{41}$ Smyth linked this order to these depictions of spatial arrangements: 'when several tribes meet, the sites for the miams are selected in accordance with rules, the arrangement generally being such as to show exactly from what direction each tribe has come. ${ }^{42}$ This cultural information created a theme within Smyth's work that traditional Aboriginal communities had been organised, structured and contained, and he made use of the term nation to describe Aboriginal political organisation: 'Large tracts, with well marked natural boundaries, are peopled by "nations", each composed of many separate tribes, differing amongst themselves but little in speech, in laws, and in modes of warfare. ${ }^{\prime 43}$

In fact, this is the material that proved to be the most controversial aspect, as Smyth, in his short discussion of Aboriginal politics, which noted consensus based decision-making and the role of clan heads in communities, went so far as to suggest that Aboriginal leadership could 'serve as a model to peoples claiming to be civilised but more inclined to vices than the Australians' ${ }^{44}$ What appears to be a quite simple statement was strongly contested within later Victorian anthropological writing. LR Hiatt describes how this was first disputed by Curr, who believed there was no Aboriginal government, only the fear of sorcery, and then subequently defended by Howitt, who believed that while sorcery was important, government was also strong. ${ }^{45}$ Diane Barwick describes how Curr's scathing criticism accused Smyth of being 'no bushman' and of not understanding Aboriginal people 'in their savage state', and yet, as she notes, these chapters 'came substantially' from information provided by Thomas, as a result of the years he had spent living amongst Woiwurrung and Boonwurrung communities. $^{46}$

While Smyth's recognition of Aboriginal political systems was controversial, his arguments were not nearly so strongly stated as the depictions of Aboriginal political systems included in the records of the first Protectorate. One of Thomas's

39 Smyth, The Aborigines of Victoria: 124.

40 Smyth, The Aborigines of Victoria: xxx.

41 Smyth, The Aborigines of Victoria: $\mathrm{xxx}$.

42 Smyth, The Aborigines of Victoria: xxx.

43 Smyth, The Aborigines of Victoria: xiii.

44 Smyth, The Aborigines of Victoria: 129.

45 LR Hiatt, Arguments about Aborigines: Australia and the Evolution of Social Anthropology, Cambridge University Press, Cambridge, New York and Melbourne, 1996: 87-88.

46 Quoted in Diane Barwick, Rebellion at Coranderrk, Laura E Barwick and Richard E Barwick (eds), Aboriginal History Inc., Canberra, 1998: 109. 
pieces of earlier writing, which appears to have been written with an eye for publication, entitled 'my first journey with the blacks', clearly documents the extent he relied on the Woiwurrung clan head, and most senior Kulin leader, Billibellary, for his safety after his first attempts to move Aboriginal people out of Melbourne to establish a station at Arthur's Seat on the Mornington Peninsula. ${ }^{47}$ In Dredge's writings in the notebook of collated material in Smyth's archive of papers, politics is even more clearly explained:

It does not appear that there are any persons amongst them which have Kingly authority over the rest. Yet each sub division of a tribe has one or more leading man or men. And in all important matters which require the assemblage of the whole tribe these influential men debate upon Public Matters, and decisions are come to be mutual consent. This kind of debating usually occurs in the evening ... and sometimes long and animated speeches are delivered. ${ }^{48}$

In Smyth's text, while Aboriginal political systems are outlined in a general sense, the vitally important role of Aboriginal leadership in mediating colonial relationships, and negotiating on behalf of communities, was not included. Both historical and contemporary leaders were barely mentioned, despite the continuation of Aboriginal political relations on reserves during the time when Smyth was Secretary of the Board, as described by Barwick: 'In the 1870s those Kulin assembled at Coranderrk were still influenced by ancient rules governing marriage, land ownership and political authority.' ${ }^{49}$ The exception to including information about particular Aboriginal leaders was when Smyth was describing Aboriginal racial types; Billibellary, the most senior Kulin clan head at the time of first European settlement, was included in the text merely as a figure to illustrate that Aboriginal people also differentiated between racial groups. By contrast, Billibellary appears as a central figure in Thomas's narratives, as a leader on whom he relied for cultural information and for influence, as someone who had protected him physically on occasions. ${ }^{50}$ Simon Wonga, Billibellary's son and successor, was described merely as 'the principal man of the Yarra tribe ... Wonga has a mild disposition, and is always gentle and courteous. He is a good speaker, and has much influence with his people.' His photograph, as well as that of his wife, was included within a montage that was seen to exemplify an Aboriginal racial type. The names of other people living on reserves were included along with their height, weight and age to ascertain the characteristics

\footnotetext{
47 See Rachel Standfield, 'Protection, settler politics and indigenous politics in the work of William Thomas', Journal of Colonialism and Colonial History 13(1), Spring 2012.

48 William Thomas, undated notebook within the Robert Brough Smyth papers, SLV MS 8781, Box 1176/6: 106.

49 Barwick, Rebellion at Coranderrk: 12.

50 Standfield, 'Protection, settler politics and indigenous politics'.
} 
of the Aboriginal racial type. ${ }^{51}$ Information about Aboriginal leaders was included here as Smyth declared he was attempting to overcome the previous depiction of Aboriginal people in racial thought, having been

harshly dealt with in nearly all the works that treat of ethnology. In many their faces are made to appear as like those of baboons as possible; and though it must be confessed that, as a rule, neither the men nor the women have pleasing countenances, they are as thoroughly human in their features and expression as the natives of Great Britain. ${ }^{52}$

Specific information about leadership was replaced with general points about racial characteristics, with Aboriginal leaders seen as exemplars of the characteristics and attitudes of Aboriginal society.

While politics, leadership and order in Aboriginal societies were themes in Smyth's text, they sat alongside another, that of 'superstition' and its supposedly central role in Aboriginal cultural life. Stressing the role of superstition in Aboriginal community life worked to undermine the idea of order within Aboriginal societies that Smyth's explanation of relationships to country, leadership and politics conveyed. No matter what admiration Smyth may have had for Aboriginal order, he could not admire Aboriginal life in general. In his introduction, Smyth described leadership and gathering by communities, but then goes on, 'there are endless sources of enjoyment when a large meeting takes place; but on the whole the life of a savage is one of trouble', said to be caused by hunger, the climate, sorcery and women. ${ }^{53}$

When Thomas had summed up Kulin leadership, he had done so in the following manner: 'Their government is patriarchal, the head of each family having control over his household ... Each tribe has a chief who directs all its movements, and who, wherever he may be, knows well where all the members of the community are.' Thomas followed up this statement by identifying the other 'eminent men', including 'warriors, counsellors, doctors, dreamers who are also interpreters; charmers' ${ }^{54}$ As Hiatt shows, Smyth included a similar comment 'but embellished Thomas's formulation, and extended it to the whole of Victoria', suggesting that the 'principal man of the tribe' enacted the decisions of others:

There are the doctors and sorcerers who under some circumstances have supreme power; there are the warriors who in time of trouble are absolute masters; there are the dreamers who direct and control movements of the tribe until the divinations are fulfilled or forgotten; there are the old

51 Smyth, The Aborigines of Victoria: 10, 9.

52 Smyth, The Aborigines of Victoria: 11.

53 Smyth, The Aborigines of Victoria: xxxi.

54 Quoted in Hiatt, Arguments about Aborigines: 126. 
2. 'Thus have been preserved numerous interesting facts that would otherwise have been lost'

men - councillors - without whose advice even the warriors are slow to move; and finally there are the old women who noisily intimate their designs, and endeavour by clamour and threats to influence the leaders of the tribe..$^{55}$

While Smyth, drawing on the observations of Thomas and Dredge, suggested that decision-making was consensus based, there was a subtle shift in wording here which places new emphasis on the role of doctors and sorcerers, as well as a focus on divination, and the suggestion that Aboriginal women were engaged in 'clamour and threats'. The original argument about order in politics and leadership is thus diluted into one of a chaotic society ruled by superstition.

Importantly, superstition supposedly undermined the Aboriginal community's ability to deal with disease, the cataloguing of which was an important aspect of Smyth's text, as was Aboriginal weakness in the face of disease and refusal to seek help from colonial doctors:

It is undoubtedly true that the modes of treatment adopted by Europeans are not, as a rule, successful, if the black be at all under the influence of his own people ... Then the old superstitions are strong upon him ... He fears the white man, dreads his medicine, and shrinks from the outward applications which may, for aught he knows, be possessed of secret properties that will cause his destruction ... The European doctor indeed is always at a great disadvantage when dealing with the natives; and though medical men are in Victoria most zealous and painstaking at all the Aboriginal Stations, they are thwarted continually by the people for whose benefit they use their utmost skill. ${ }^{56}$

Patrick Brantlinger's work has documented this central role of superstition in dying race discourse, which allowed population decline in Indigenous communities to be explained away in ways that downplayed the effects of colonisation, allowing the idea of extinction of Indigenous peoples to become a 'massive and rarely questioned consensus' ${ }^{57}$ As Brantlinger argues, 'savage customs' including 'superstition' took precedence over violence and disease in many accounts of population decline, such that 'savagery, in short, was frequently treated as self-extinguishing ${ }^{\prime}{ }^{58}$ Smyth linked savagery to death by disease in a way that recognised the role of disease in population decline, but placed the blame back on Aboriginal people for its effects, and, at the same time, applauded the role of European doctors. Aboriginal belief in their own medical systems and wariness of European doctors, described in terms of the 'old

55 Hiatt, Arguments about Aborigines: 126.

56 Smyth, The Aborigines of Victoria: 259-260.

57 Brantlinger, Dark Vanishings: 1.

58 Brantlinger, Dark Vanishings: 2. 
superstitions', led Smyth to depict Aboriginal people as a dying race, declaring that 'it is probable that the numbers will decrease, and that, as a race, they will ultimately be extinguished in Victoria' ${ }^{59} \mathrm{He}$ did so even in direct contradiction to estimates from John Green he included in his text, and Board reports from 1869, which had concluded that 'the Board does not hesitate to declare that the oft-repeated statement that the race is rapidly disappearing is by no means in accordance with fact ${ }^{\prime}{ }^{60}$ So while Smyth was happy to contradict other accepted wisdom about Aboriginal people, he concurred with views that Aboriginal people would become extinct. He suggested this was because of Aboriginal loss of country and loss of liberty, but his lack of discussion of colonisation and his emphasis on superstition, meant that this seemed a mysterious force, rather than a clash between settlers and Indigenous peoples.

Robert Brough Smyth's text made heavy use of the work of William Thomas and other material from the Port Phillip Protectorate, the original attempt at 'protection' of Aboriginal people in Victoria during the late 1830s and 1840s. By interrogating just a small portion of the archive of ethnographic observation on which Smyth's two-volume work was based, it is possible to trace the way that this anthropological text sat within the context of colonial governance of Aboriginal people in Victoria, and trace the archive as a site of knowledge production rather than simply a repository of 'facts'. The relationships between ethnographic observation and Indigenous informants, which had been pronounced in the period of the first Protectorate, were removed in the context of developing a detached scholarly text. Smyth included material about Aboriginal cultural life derived from these early colonial relationships, but presented this as characteristic of a 'racial type'. In attempting to overcome negative perceptions of Aboriginal people, and counter racial prejudice, the text did explore issues of land and leadership, but did so in abstract terms. Smyth's text might have been based on descriptions of specific events and cultural characteristics, but in stripping them of detail rendered Aboriginal people ahistorical and timeless, their contemporary lives divorced from colonial history and dispossession. With the advent of a 'moral' policy of protection legislation to 'ameliorate' the conditions of Aboriginal life, the 'frontier period' of just a generation before was rendered as the 'olden times'. In Smyth's text, Aboriginal people required protection and government amelioration, not from the direct forces of white settlement, but from their own weakness and superstition, and ultimately despite the efforts of colonial governments, doctors and protectors, Smyth envisaged extinction for Aboriginal Victorians.

59 Smyth, The Aborigines of Victoria: 45.

60 Smyth, The Aborigines of Victoria: 44. 